\title{
Self-Inclusion and Dissociation of a Bridging $\beta$ - Cyclodextrin Triplet
}

\author{
Bo Gao, Gengxin Wang, Bao Li and Lixin Wu* \\ State Key Laboratory of Supramolecular Structure and Materials, College of \\ Chemistry, Jilin University, Changchun, 130012, P.R. China \\ E-mail:wulx@jlu.edu.cn
}

\begin{tabular}{|c|c|}
\hline \multicolumn{2}{|c|}{ Contents } \\
\hline Characterizations of compounds & Figure S1-S7 \\
\hline 2D NMR Spectra in different solvents & Figure S8-S10 \\
\hline Studies of host-guest interactions & Figure S11-S13 \\
\hline
\end{tabular}




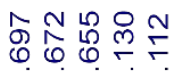

NNiN

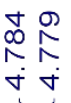

คิ่

กั่

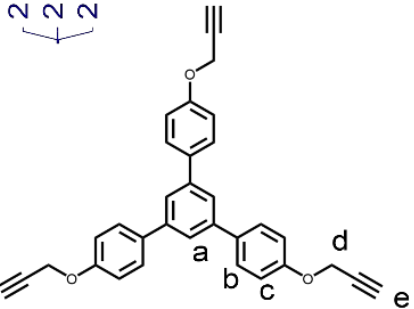

d

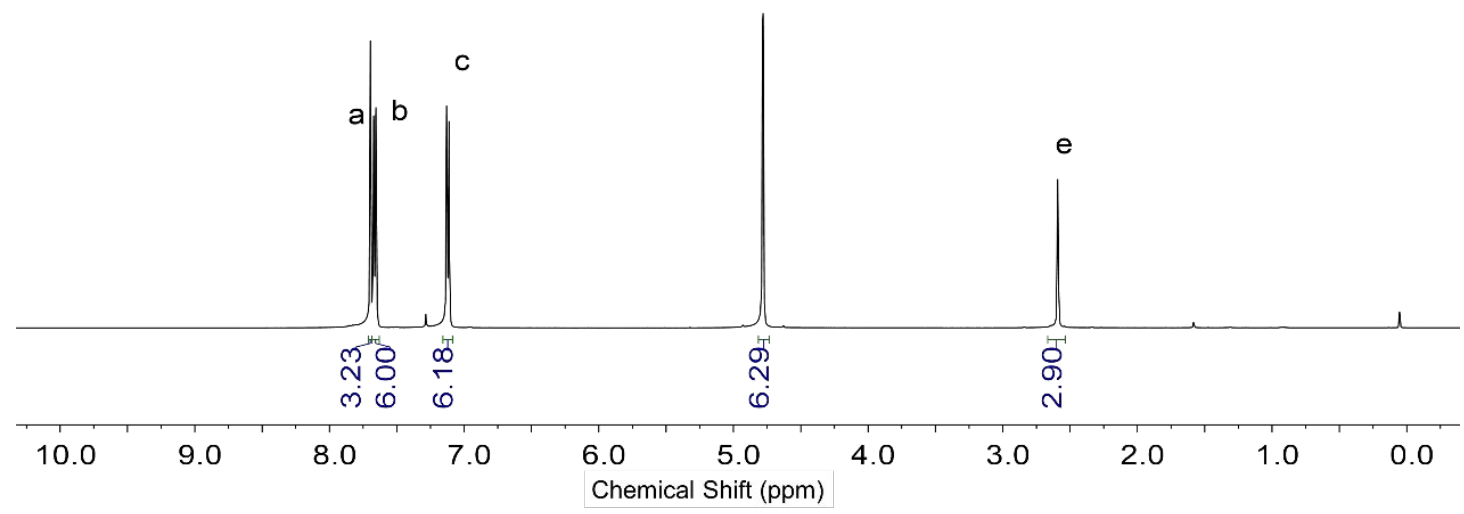

Figure S1 ${ }^{1} \mathrm{H}$ NMR spectrum of 1,3,5-tris-(4-(prop-2-yn-1-yloxy)phenyl)-benzene in $\mathrm{CDCl}_{3}$.

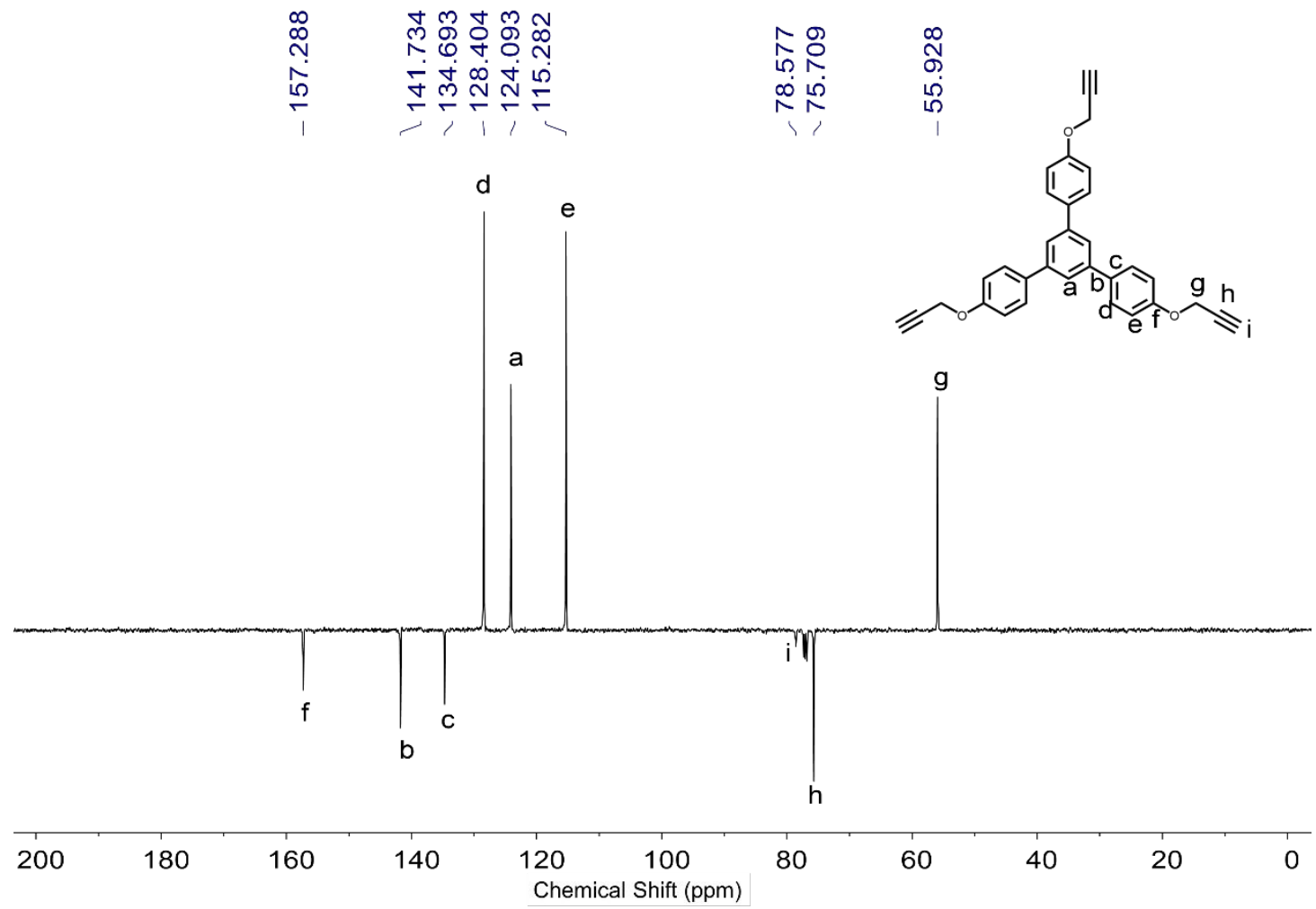

Figure S2 ${ }^{13} \mathrm{C}$ NMR DEPTQ spectrum of 1,3,5-tris-(4-(prop-2-yn-1-yloxy)phenyl)-benzene in $\mathrm{CDCl}_{3}$. 


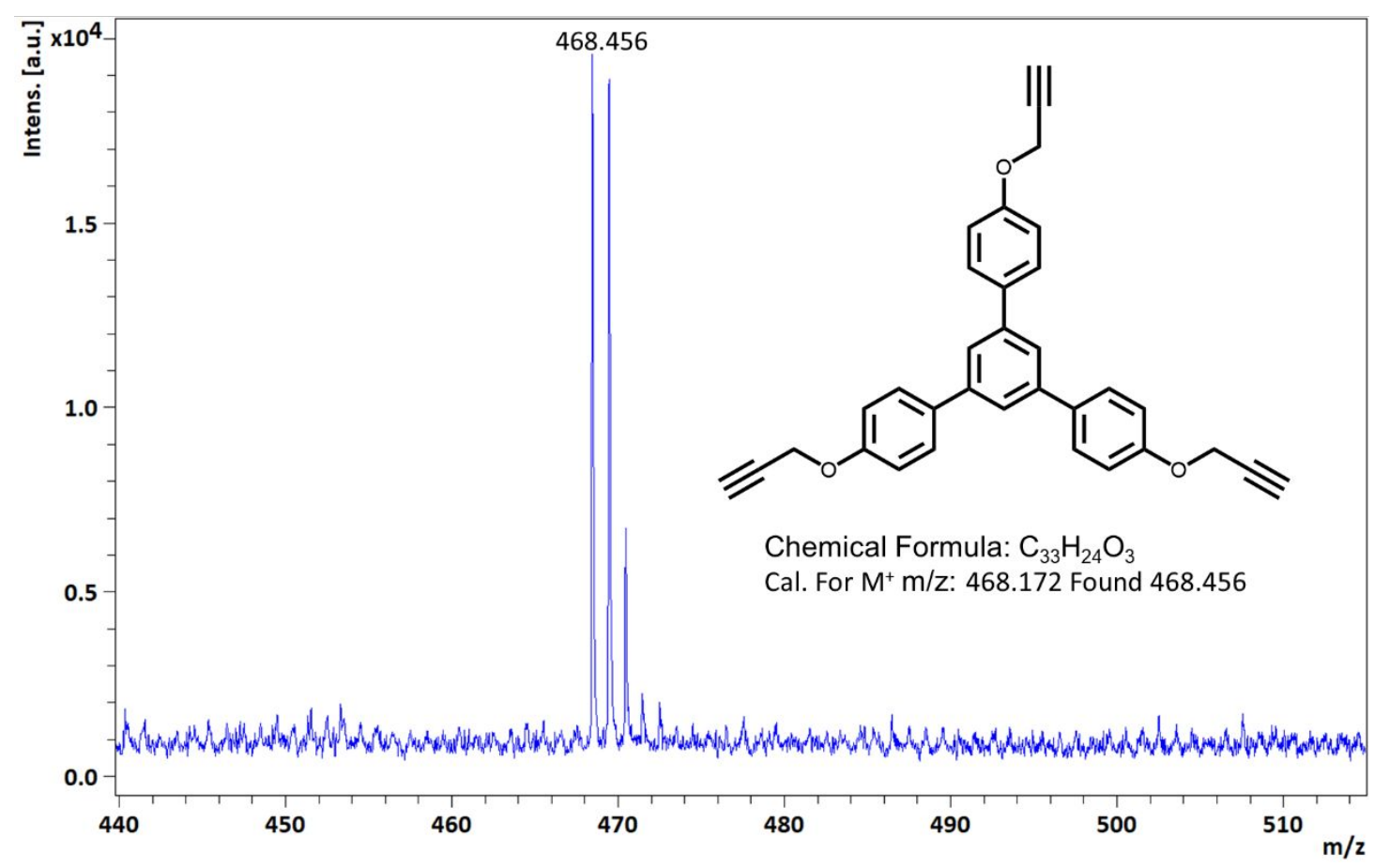

Figure S3 Maldi-tof MS spectrum of 1,3,5-tris-(4-(prop-2-yn-1-yloxy)phenyl)-benzene.

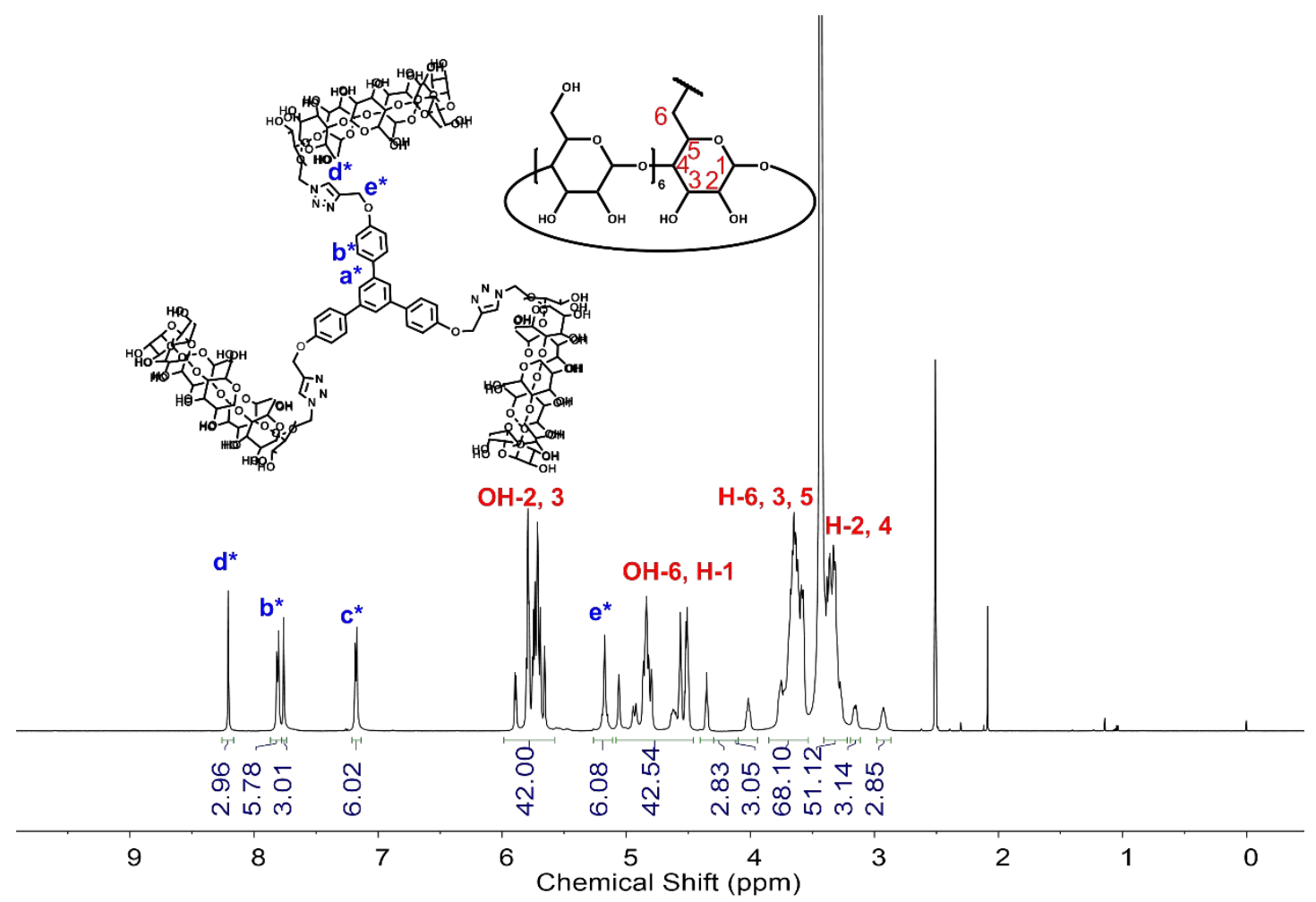

Figure S4 ${ }^{1} \mathrm{H}$ NMR spectrum of tri-CD in DMSO- $d_{6}$. 


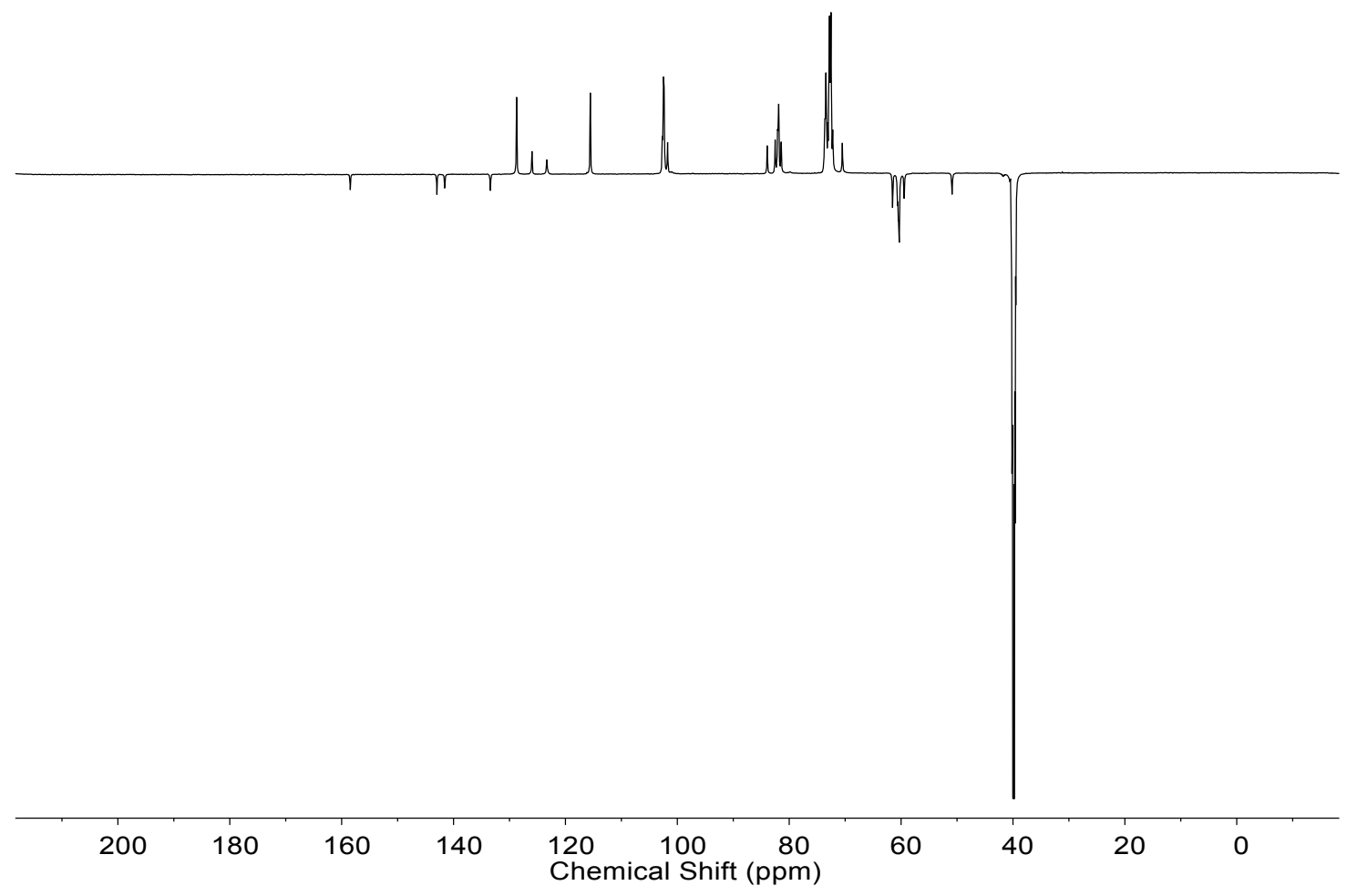

Figure $S 5{ }^{13} \mathrm{C}$ DEPTQ NMR spectrum of tri-CD in DMSO- $d_{6}$.

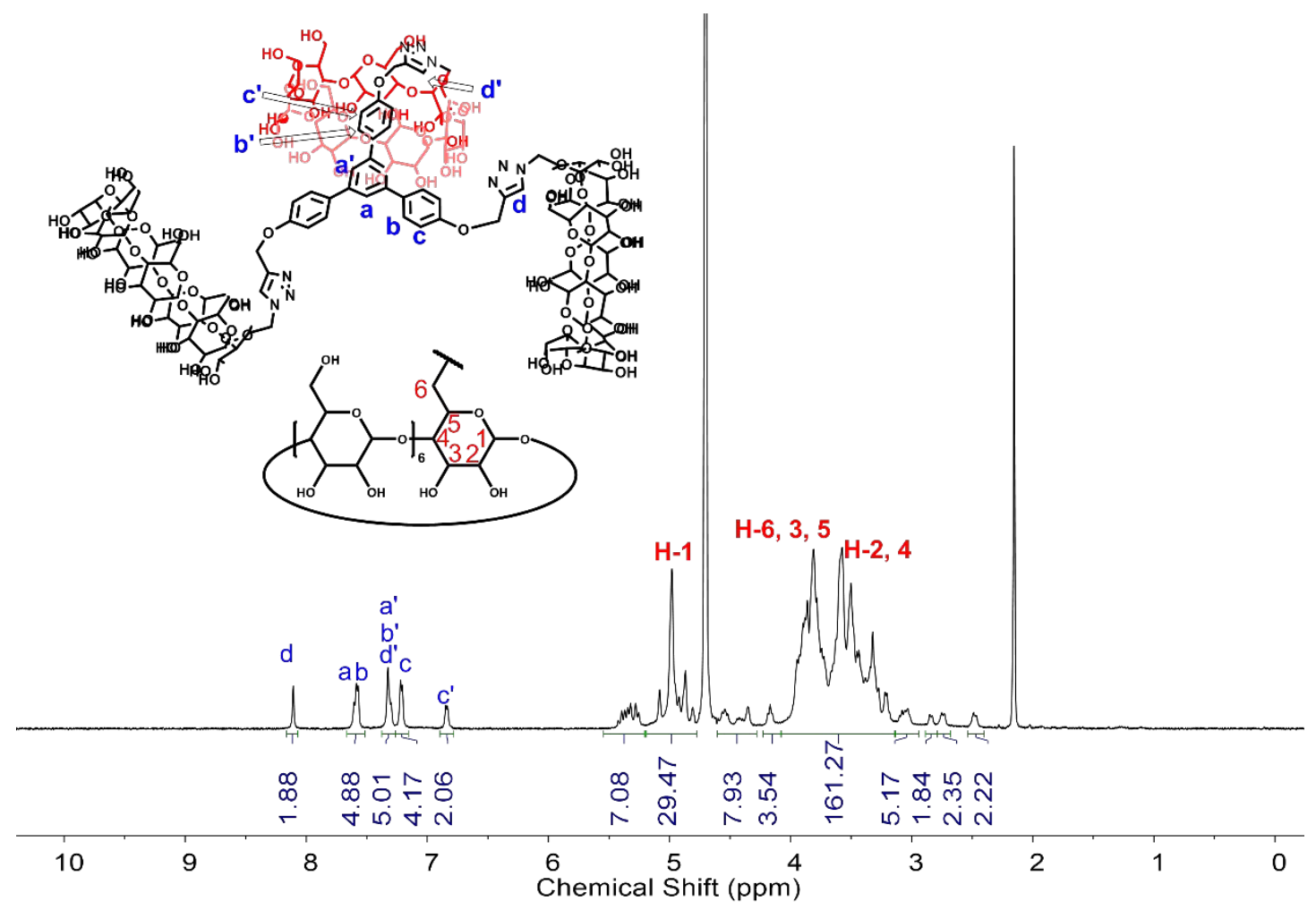

Figure $S 6{ }^{1} \mathrm{H}$ NMR spectrum of tri-CD in $\mathrm{D}_{2} \mathrm{O}$. 


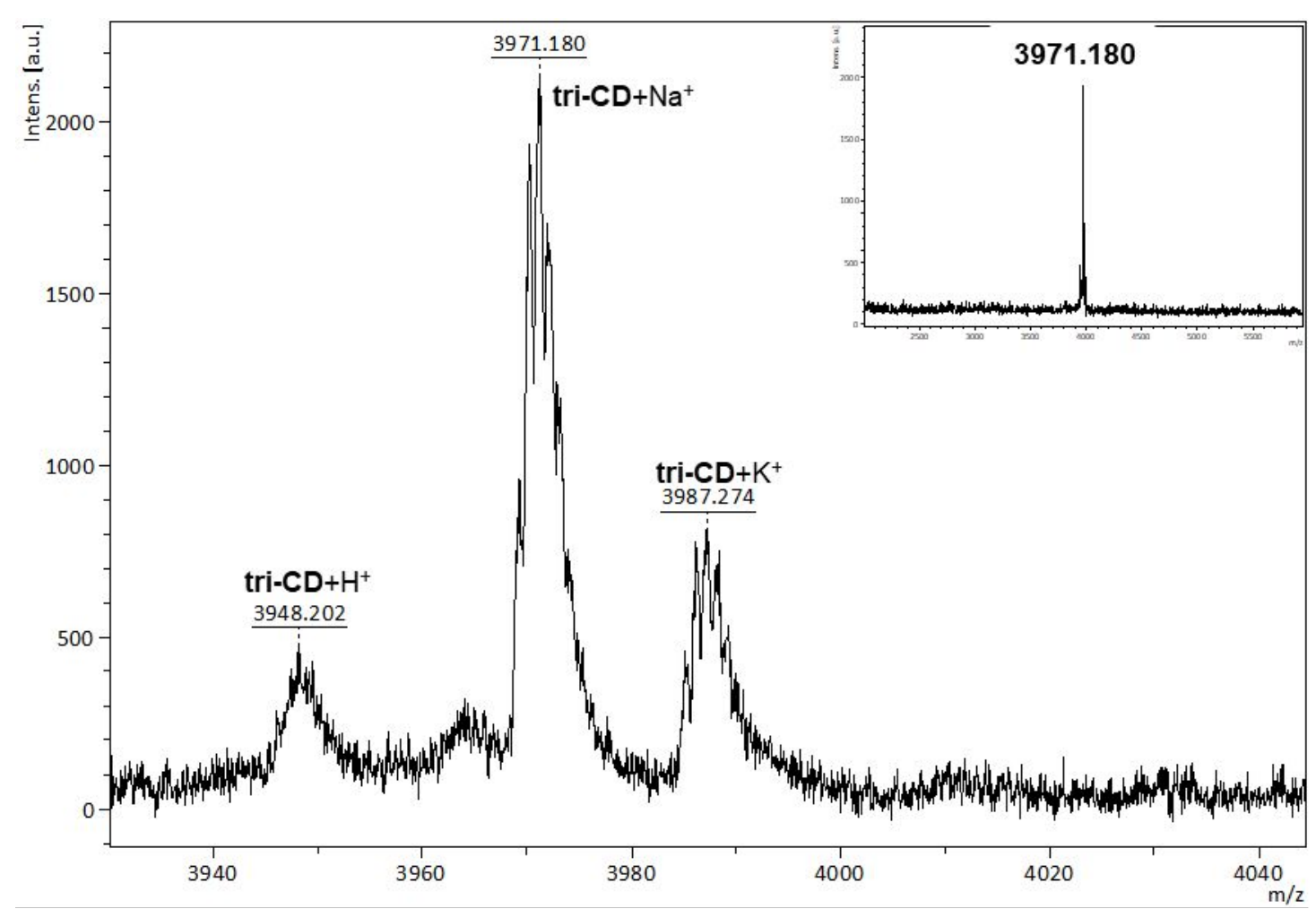

Figure $\mathbf{S 7}$ Maldi-tof MS spectrum of tri-CD.

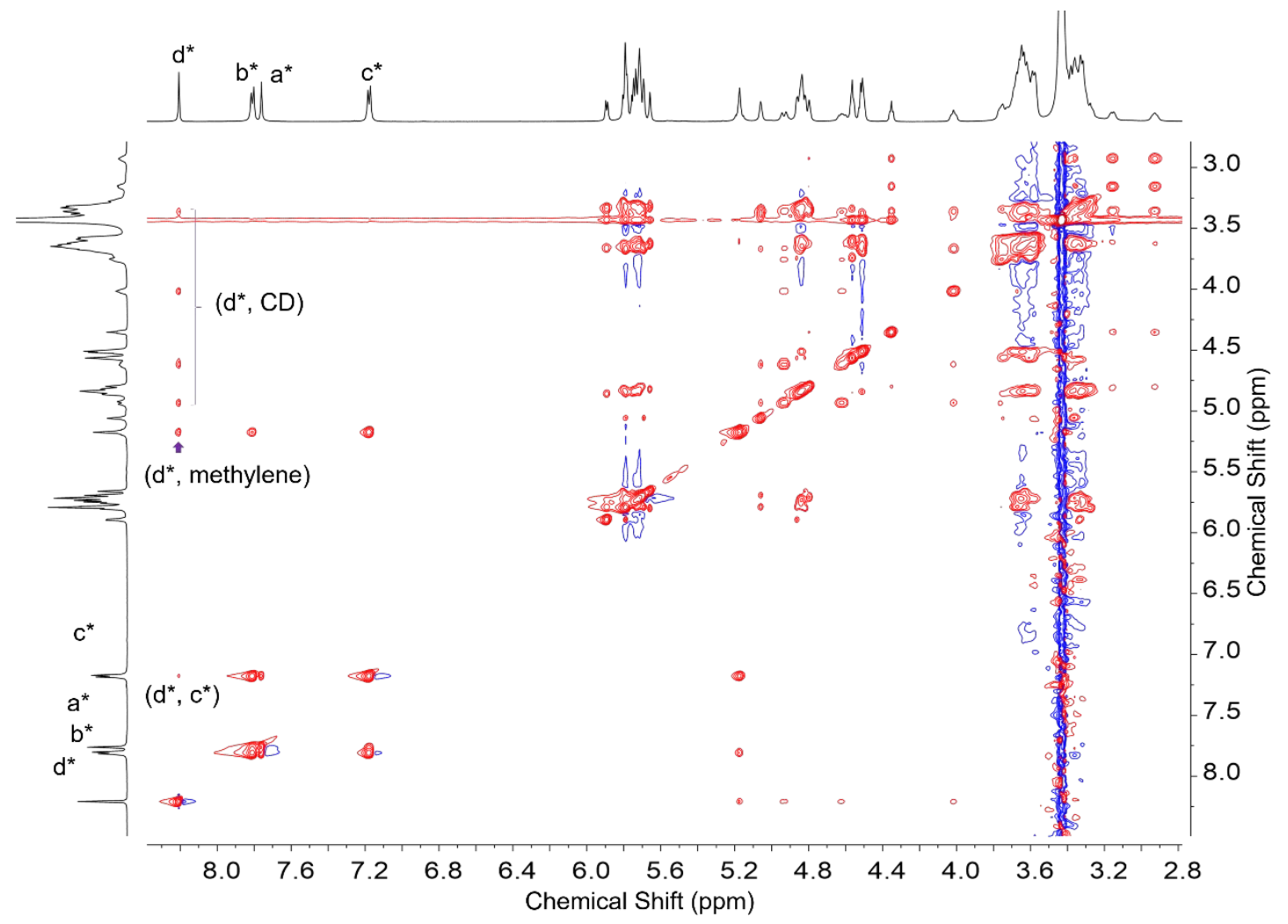

Figure S8 2D NOESY NMR spectrum of tri-CD in DMSO- $d_{6}$. 


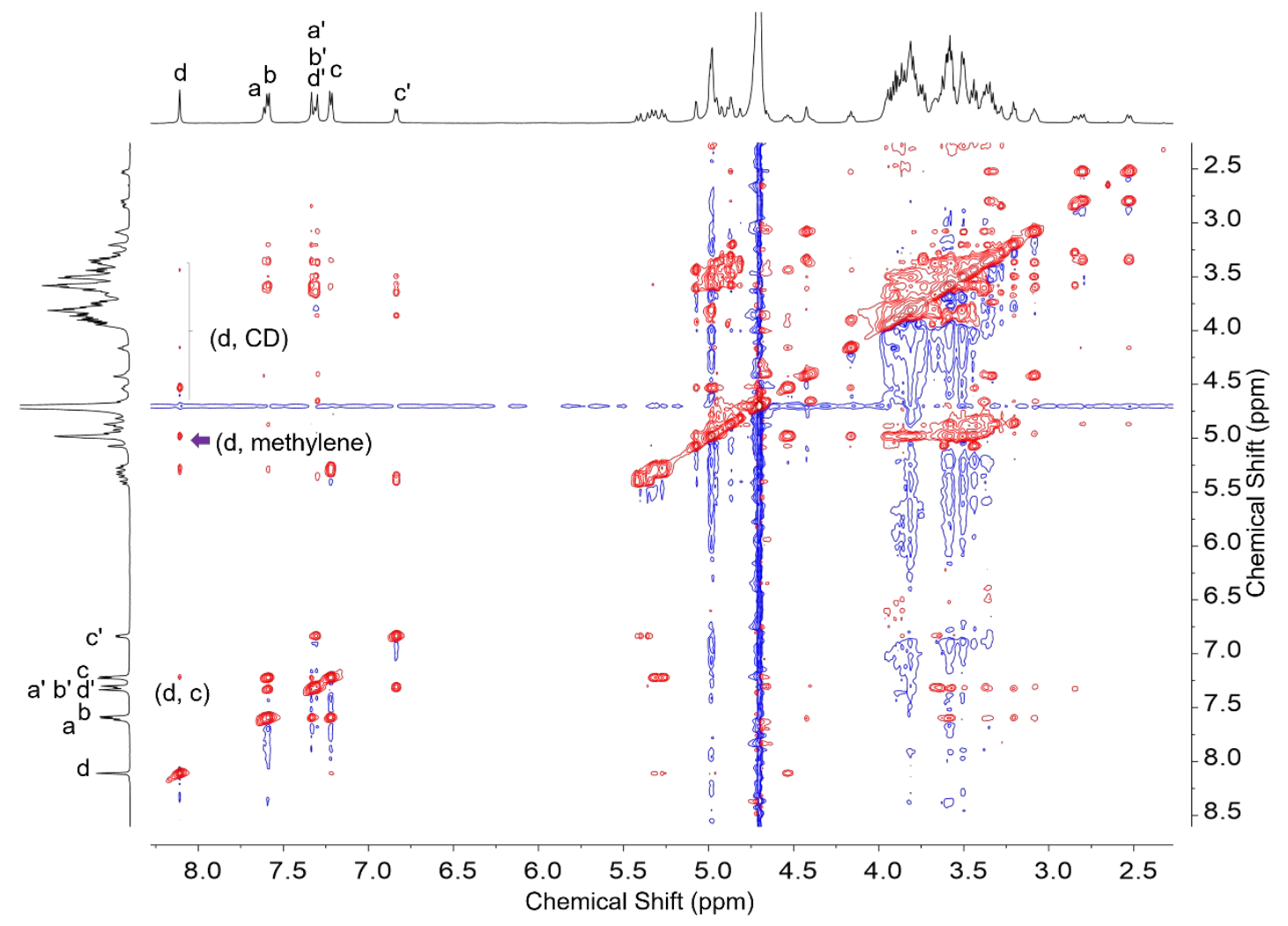

Figure S9 2D NOESY NMR spectrum of tri-CD in $\mathrm{D}_{2} \mathrm{O}$.

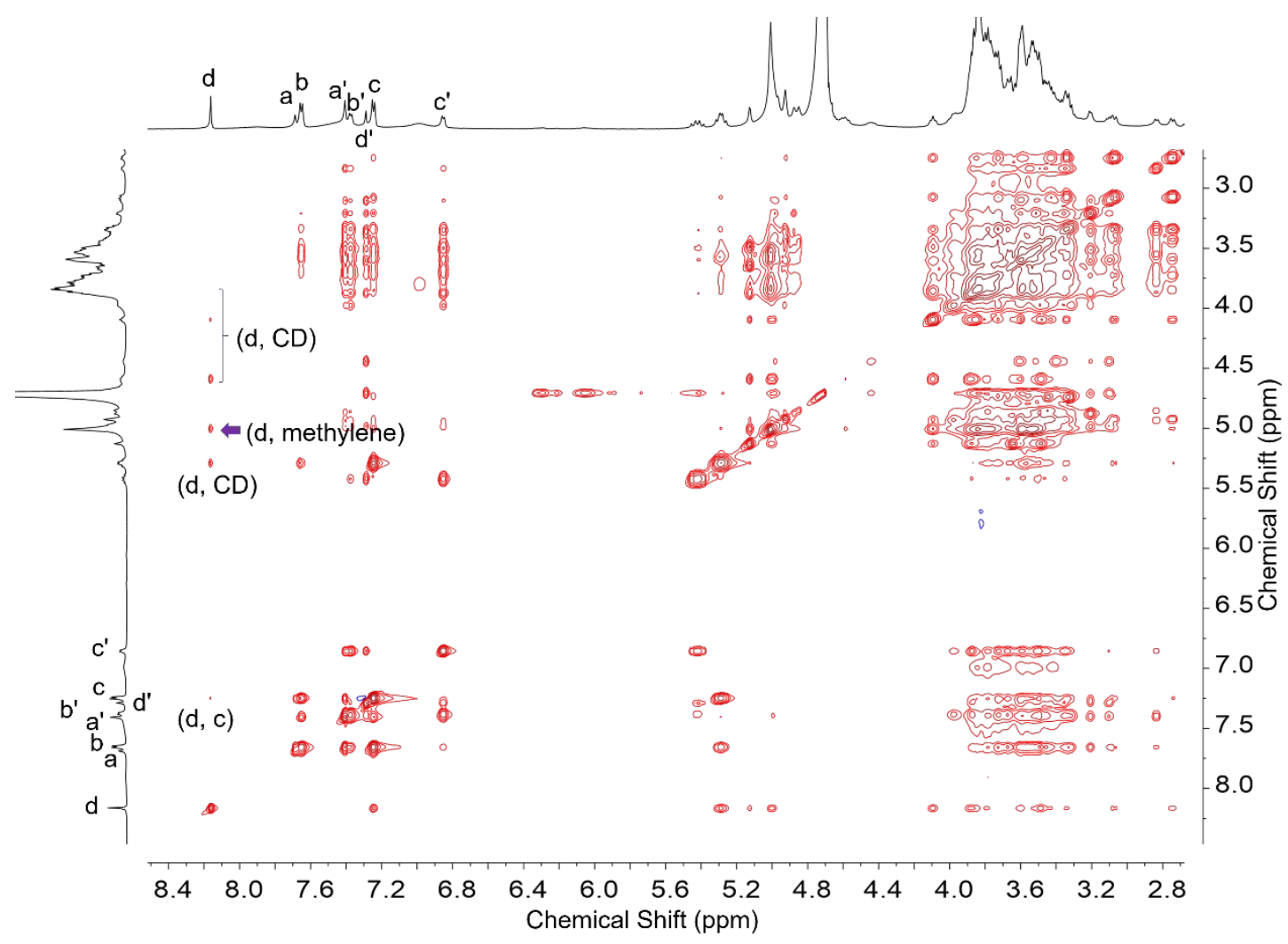

Figure S10 2D NOESY NMR spectrum of tri-CD in $20 \%$ DMSO/ $\mathrm{D}_{2} \mathrm{O}$. 


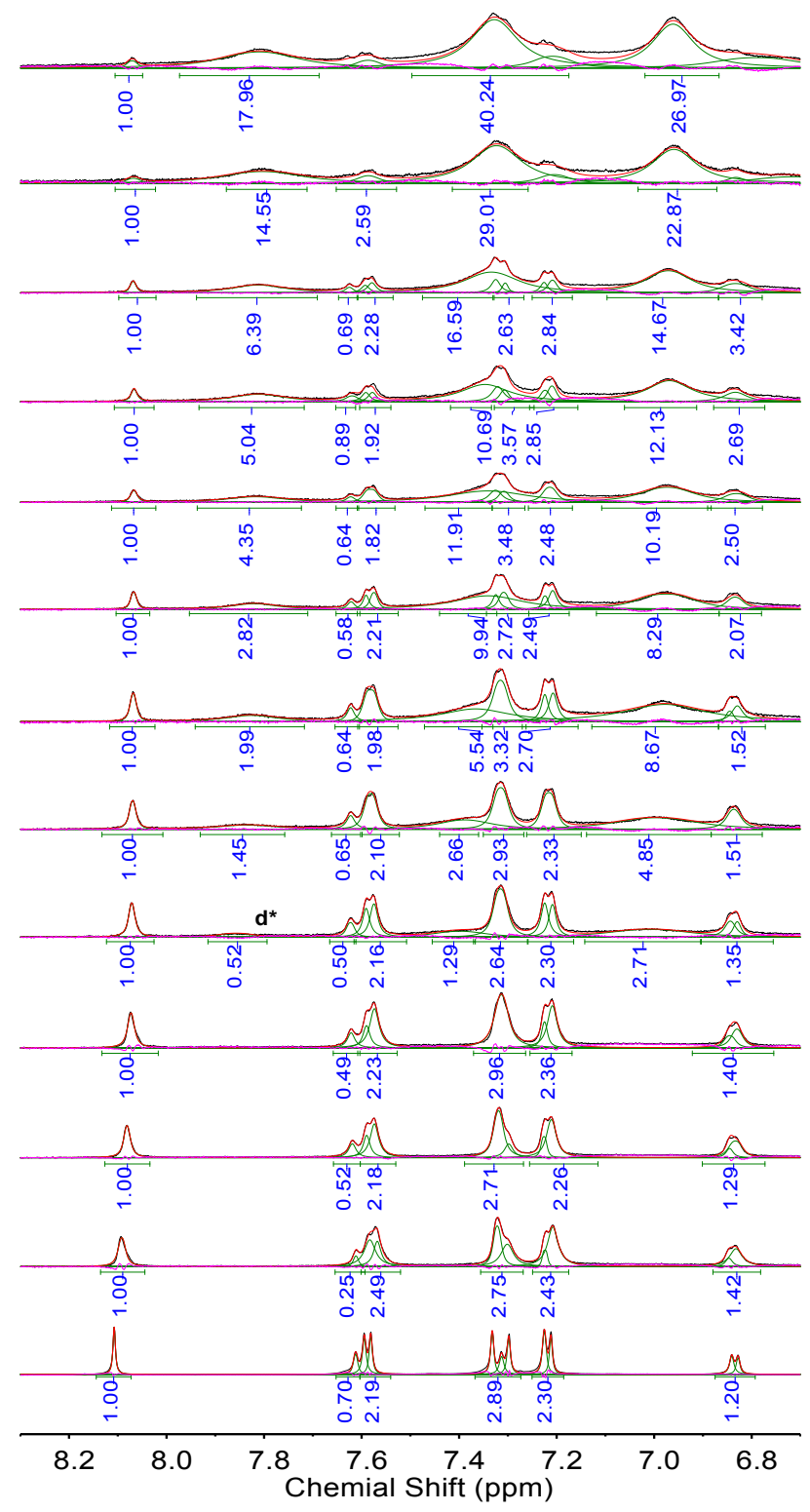

Figure S11 ${ }^{1} \mathrm{H}$ NMR spectrum of tri-CD fixed at $1 \mathrm{mM}$ and ada3 change from 0 to $20 \mathrm{mM}$ in $\mathrm{D}_{2} \mathrm{O}$.

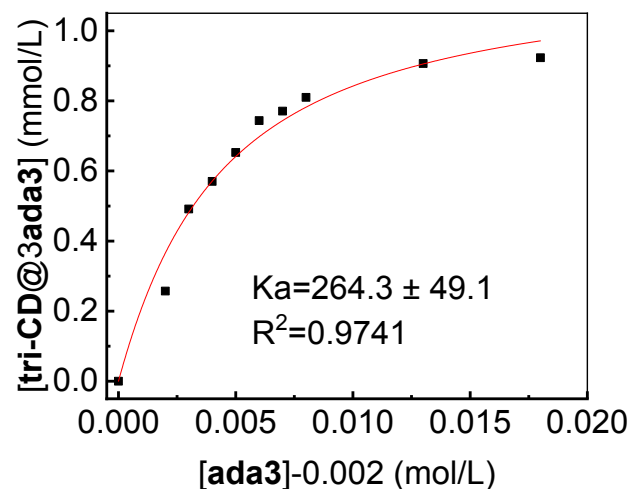

Figure S12 Plot the concentration of 1:3 host-guest complex deduced from the integral area of peak $\mathbf{d}^{*}$ and the abscissa recalculated to be [ada3]-0.002 $\mathrm{mM}$ as the real concentration interacting with tri-CD and $K_{a}$ value is calculated to be $264 \pm 49$. 
a)
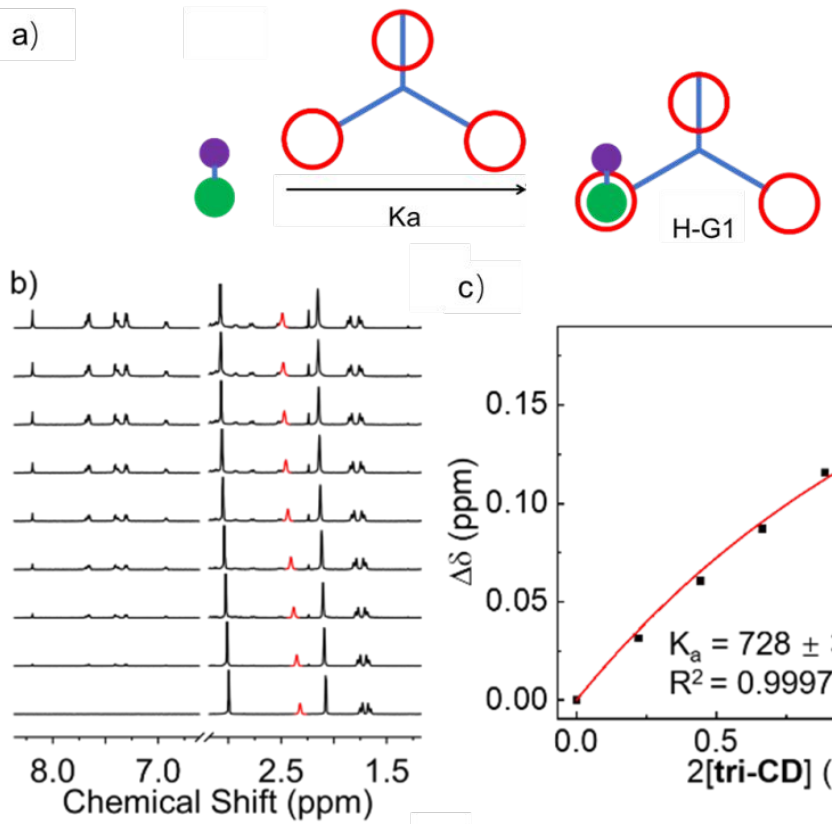

c)

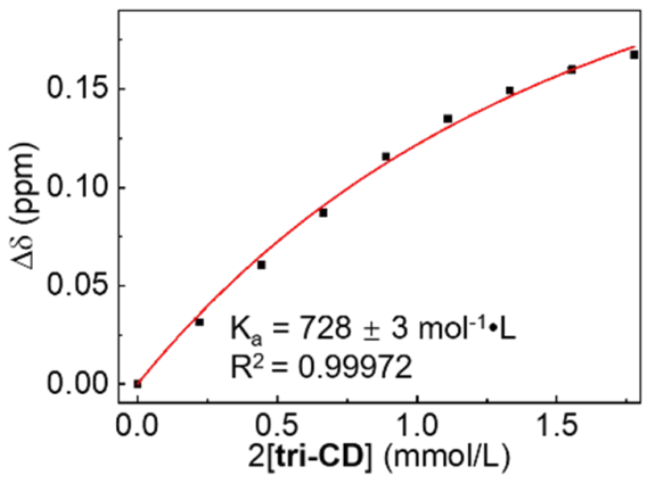

d)

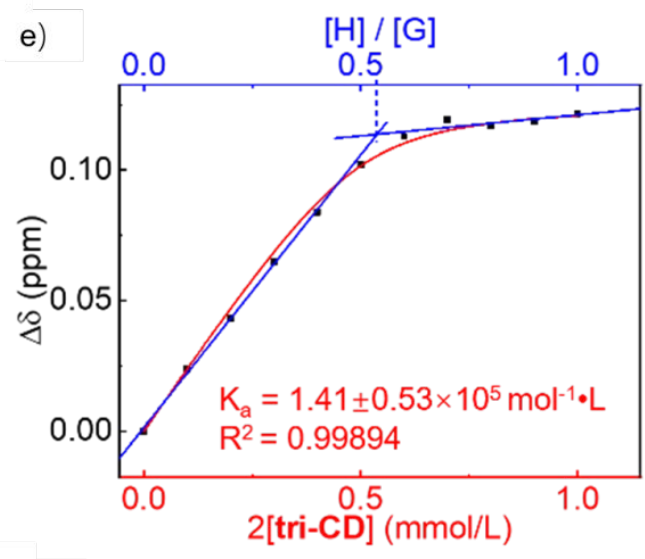
f)

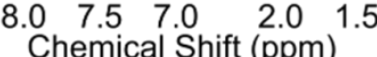

g)
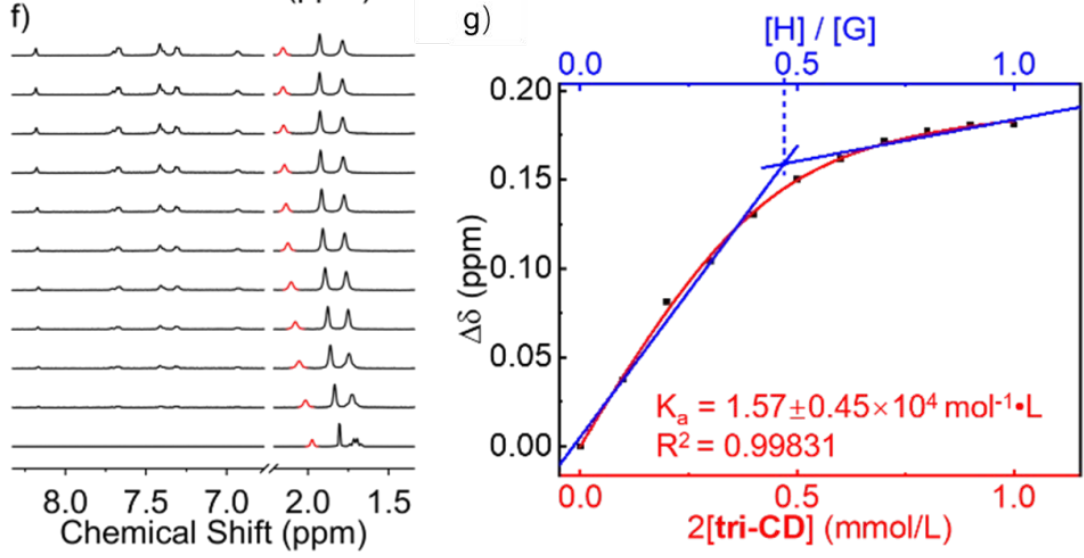

Figure S13 (a) Schematic diagram for process-1; partial NMR titration spectra and plots, (b) ada1 fixed at $1 \mathrm{mM}$, tri-CD changed from 0 to $1 \mathrm{mM}$; (d) ada2 fixed at $0.5 \mathrm{mM}$, tri-CD changed from 0 to $0.5 \mathrm{mM}$; (f) ada3 fixed at $0.5 \mathrm{mM}$, tri-CD changed from 0 to $0.5 \mathrm{mM}$; (c), (e), (g) plots of peaks painted red in the left spectra respectively, non-linear fitting curve painted red for calculating $\mathrm{K}_{\mathrm{a}}$ corresponds the red axis and linear fitting for calculating stoichiometric ratio painted blue corresponds the blue axis. 